\title{
Estimation of container system development in a region
}

\author{
Daria Kochneva ${ }^{1, *}$, Vasily Say ${ }^{1}$, and Valentina Parshina ${ }^{1}$ \\ ${ }^{1}$ Ural State University of Railway Transport, 620034 Yekaterinburg, Russia
}

\begin{abstract}
A relevant problem of scientific research is formalization of the processes of interaction between transportation systems and the region in the context of modern ideas of synergetic approach. The purpose of this article is to develop a methodology for assessing and forecasting the needs of a region for container transport system development. The methodology includes two elements. First is the model for forecasting region's demand for container transportation based on the methods of correlationregression analysis, index prediction and the Monte Carlo method. Second is the imitation model for assessing the needs of the region in the technical and organizational development of the container system. Organizational development is achieved due to system integration of market players, coordinated management of container flows, which makes it possible to establish the synergistic effect availability.
\end{abstract}

\section{Introduction}

Container transportation has been the most dynamically developing type of cargo transportation in recent years. The average level of containerization in the world is $60-70 \%$ of the total volume of dry cargo transportations [1]. In Russia, this indicator is significantly behind the global level and presently amounts to $6.2 \%$ only, but it has been growing at a rapid pace over the past decade and the containerization factor on the railway network has more than doubled [2].

The reasons for rapid development of the container market in the regions of Russia are growth of industrial production, intensification of foreign trade with the countries of the Asia-Pacific region, redistribution of freight traffic from other types of rolling stock towards containers. This caused a significant increase in the need for container infrastructure in the regions and formation of a competitive container market.

At the same time, there is currently no single coordination approach to assessing the need for regions to develop container infrastructure, so formation of regional container systems is often spontaneous. Each transport market player pursues only its own economic interests, which causes an imbalance in development of terminal capacities in the region, the emergence of irrational empty container flows, and the inefficient use of rolling stock. In its turn, the reduction in the efficiency of operation of the container system has negative effects on development of the regional economy.

\footnotetext{
* Corresponding author: dana rich@mail.ru
} 
Arrangement of interaction between the links of the container transport system under market conditions has been the subject of a large number of modern studies. Various methods and models are used in this area, for example, cluster analysis [3], game theory models [4], supply chain management concept [5], agent-based simulation modeling [6], etc. However, the basis of these approaches primarily consists in the interests of certain companies, while the interests of the container system in general and in the specific region, the needs of which such system meets, do not receive due attention.

This determines the relevance and novelty of developing approaches to assessing the need of the region for developing the container transport system based on the balance of interests of suppliers and consumers of transport services, taking into consideration territorial economic characteristics. The basis for development of the model is the modern understanding of the system approach in logistics [7-8].

\section{Study method}

The volume of container transportations in the region is mainly determined by the following two factors: demand of enterprises for container transportation and technical development of the container infrastructure. Therefore, let us express the region's containerization level in the following function:

$$
k_{t}=F\left(D_{t} ; R_{t}\right),
$$

where $D_{t}$ is the demand of enterprises of the region for container transportation at moment of time $t$,

$R_{t}$ is the technical and technological development of the container infrastructure in the region at moment of time $t$.

Thus, solution to this task includes the following two main stages: forecasting the region's demand for container transportation and assessing the need for development of the container system to meet this demand.

Forecasting of the region's demand for container transportation can be performed with various methods. There are the following main methods of traffic forecasting among many methods proposed in the references: extrapolation of time series [9], index prediction method [10], expert methods [11], correlation-regression analysis methods [12-13], simulation modeling methods [14].

The following author's model for forecasting the demand for container transportation is proposed on the basis of the index method, regression modeling and the Monte Carlo method. First, considering the fact that the demand for container shipments is limited by the volume of the cargo fit for containers, we have the following function:

$$
D_{t}=w_{t} \cdot G_{t},
$$

where $w_{t}$ is the share of cargo fit for containers in the region at moment of time $t$;

$G_{t}$ is the total value of the region's demand for freight traffic (total freight traffic of all transport types in the region), tons.

Second, let us use the index method and put down the expression for forecasting the total freight traffic on the basis of information about the past:

$$
G_{t}=I_{G t} \cdot G_{t-1},
$$

where $I_{G t}$ is the index of growth of the total cargo flow of the region. 
Third, given that the growth of the region's freight traffic is determined by the dynamics of its economic indicators, the regression model can be used:

$$
I_{G t}=f\left(I_{1 t}, I_{2 t} \ldots I_{n t}\right),
$$

where $I_{1 t}, I_{2 t} \ldots I_{n t}$ are indices of growth of economic indicators of the region. The latter can be indices of the GRP physical volume, the index of output of goods and services, production indexes, physical turnover volume indexes, etc., can be used. Selection of indices in the proposed regression model is determined by the structure of the GRP of the region, the availability of information on the investigated parameters, the regional economy specifics. The decision to include or exclude parameters in the model is taken on the basis of the analysis of regression significance indicators (correlation coefficient, determination coefficient, Student's test, Fisher test, etc.).

Fourth, let us take into consideration the fact that the change in the growth indices in the region's economic indicators is a random variable, which is determined by a large number of difficultly predictable external factors. Therefore, the Monte Carlo method is used to express each growth index of economic indicators of the region $I_{i}$ as a random variable with the established distribution law.

Thus, taking into account expression (2) to (4), the model for forecasting the demand for container transportation in the region in general terms shall be expressed as follows:

$$
D_{t}=w_{t} \cdot G_{t-1} \cdot f\left(I_{1}, I_{2} \ldots I_{n}\right) .
$$

Let us determine the regression equation (4), establish the law and the distribution parameters of the random variable $I_{i}$ in the example of the Sverdlovsk region.

To find the regression equation, let us use the step-by-step algorithm, the essence of which is selection of a small number of variables from the large number of factor attributes (in our case, region development indices $I_{i}$ ), which contribute the most to the variation of the dependent variable (in our case, the $I_{G}$ freight traffic growth index) [15].

The following two statistically significant indicators were selected in accordance with the Student's criterion based on the regression analysis of information on the volume of freight traffic and economic indicators of the Sverdlovsk region for 25 years [16]: the GRP physical volume index in the "Processing Manufacturing" section $\left(I_{1}, \%\right)$ and the GRP physical volume index under the "Wholesale and Retail Trade" section $\left(I_{2}, \%\right)$. Then, the multiple regression linear equation will be as follows:

$$
I_{G}=0.8067 I_{1}+0.3016 I_{2}-7.5712 .
$$

With that, the multiple coefficient of determination $\left(R^{2}\right)$ for the model obtained is 0.953 , which means that in $95.3 \%$ of cases the model explains the change in the volume of freight traffic and can be used for forecasting.

In accordance with the Monte Carlo method algorithm, the laws and distribution parameters for variable $I_{1}, I_{2}$ are determined, and the calculation was performed with the help of the STATISTICA software (see Table 1).

Figure 1 shows the algorithm for predicting optimistic, pessimistic and expected level of demand for container transportations for the set forecasting horizon $T$ based on $N$ trials with a given probability of the output reliability. 
Table 1. Statistical characteristics of distribution of random values $I_{1}, I_{2}$.

\begin{tabular}{|c|c|c|}
\hline Variable & $I_{1}$ & $I_{2}$ \\
\hline $\begin{array}{l}\text { Random variable } \\
\text { distribution law }\end{array}$ & Normal & Log-normal \\
\hline Pearson criterion & $\begin{array}{l}X^{2}=7,07 ; X_{\text {crit }}^{2}(9 ; 0,05)=16,92 \\
X^{2}<X_{\text {crit }}^{2}(9 ; 0,05)\end{array}$ & $\begin{array}{l}X^{2}=5,62 ; X_{\text {crit }}^{2}(7 ; 0,05)=14,06 \\
X^{2}<X_{\text {crit }}^{2}(7 ; 0,05)\end{array}$ \\
\hline $\begin{array}{l}\text { Kolmogorov- } \\
\text { Smirnov criterion }\end{array}$ & $\begin{array}{l}\lambda=0,198 ; \lambda_{\text {crit }}(0,05)=1,358 \\
\lambda<\lambda_{\text {crit }}(0,05)\end{array}$ & $\begin{array}{l}\lambda=0,082 ; \lambda_{\text {crit }}(0,05)=1,358 \\
\lambda<\lambda_{\text {crit }}(0,05)\end{array}$ \\
\hline $\begin{array}{l}\text { Statistical } \\
\text { distribution } \\
\text { parameters }\end{array}$ & $\begin{array}{l}\text { Mathematical expectation: } \\
\mu=103.05 \\
\text { Standard deviation: } \sigma=8.43\end{array}$ & $\begin{array}{l}\text { Median: } \mathrm{Me}=101.31 \\
\text { Standard deviation: } \sigma=12.71\end{array}$ \\
\hline $\begin{array}{l}\text { Expression for } \\
\text { calculation of the } \\
\text { random value }\end{array}$ & $\begin{array}{l}I_{1}=103,05+8,43 Z \text {, } \\
\text { where } Z \text { is the random number } \\
\text { regularly distributed within } \\
\text { the interval from }-3 \text { to } 3 .\end{array}$ & $\begin{array}{l}X=101,31 \cdot e^{12,71 \cdot \lg \left(\sum_{1}^{12} Z_{i}-6\right)} \\
\text { where } Z_{i} \text { is the random } \\
\text { number regularly distributed } \\
\text { within the interval from } 0 \text { to } 1 .\end{array}$ \\
\hline
\end{tabular}

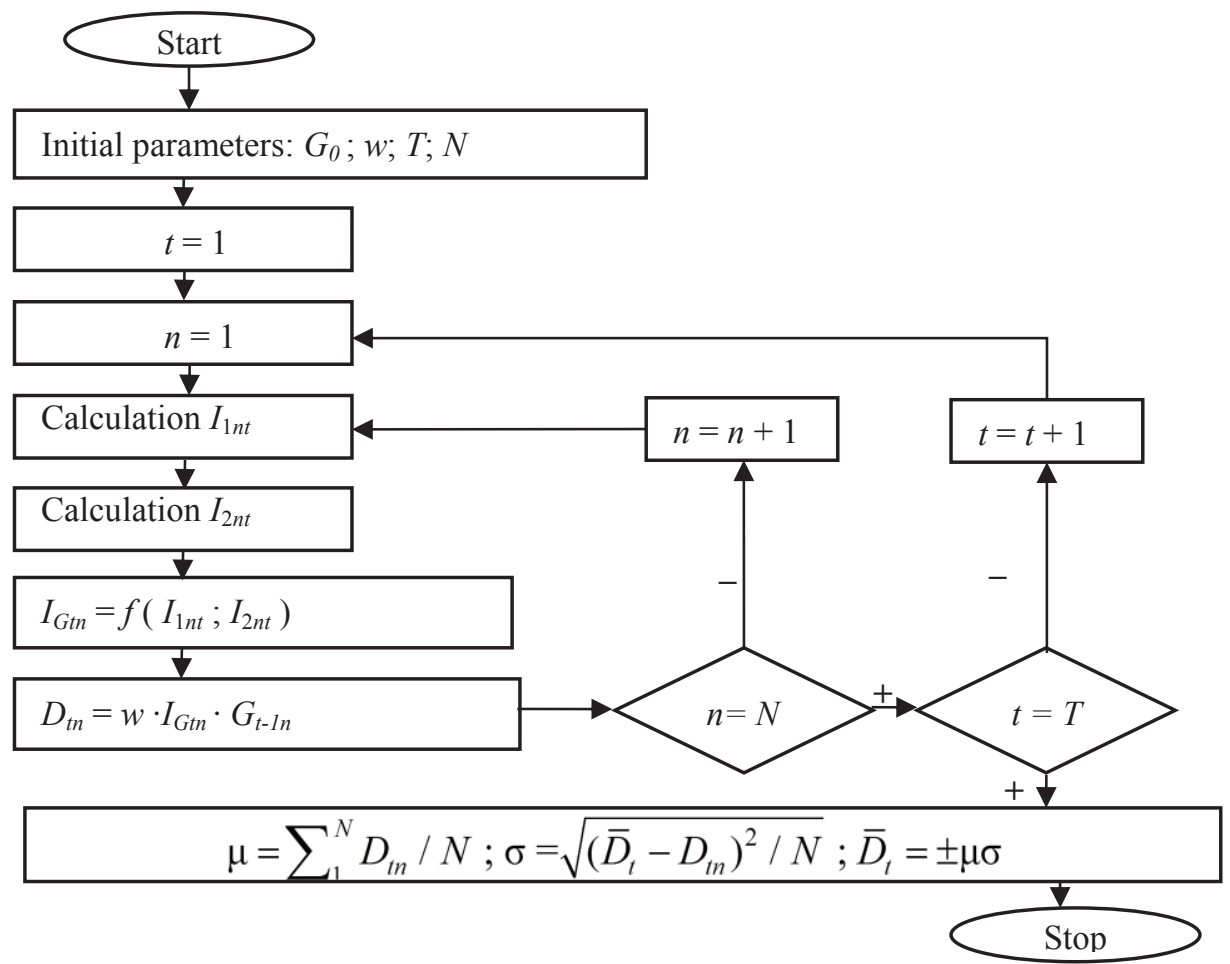

$n$ is the ordinal number of the test; $t$ is the ordinal number of the forecast period; $\lambda$ is the normalizing factor

Fig. 1. Design algorithm for forecasting the demand for container transportation. 
Based on the forecast value of demand, it is possible to estimate the need for resources of the container transport system in the region, namely: the container fleet, terminals, rolling stock. To do this, let us use the imitation model of the regional container transportation and logistics system developed by the authors in [17-18].

Ehe general view of the aforementioned imitation model can be seen in Figure 2.

The regional container system in the model representation combines a complex of technical and technological resources and a subsystem of integrated management of container traffic. Technical and technological resources of the container system shall include the following:

- the totality of terminals with the throughput of $P_{k t}$ at moment of time $t$, various owners $k$ located in the territory of the region;

- the totality of containers $A_{t}$ and fitting platforms $P_{t}$ located in the territory of the region at moment of time $t$ that belong to various owner $k$.

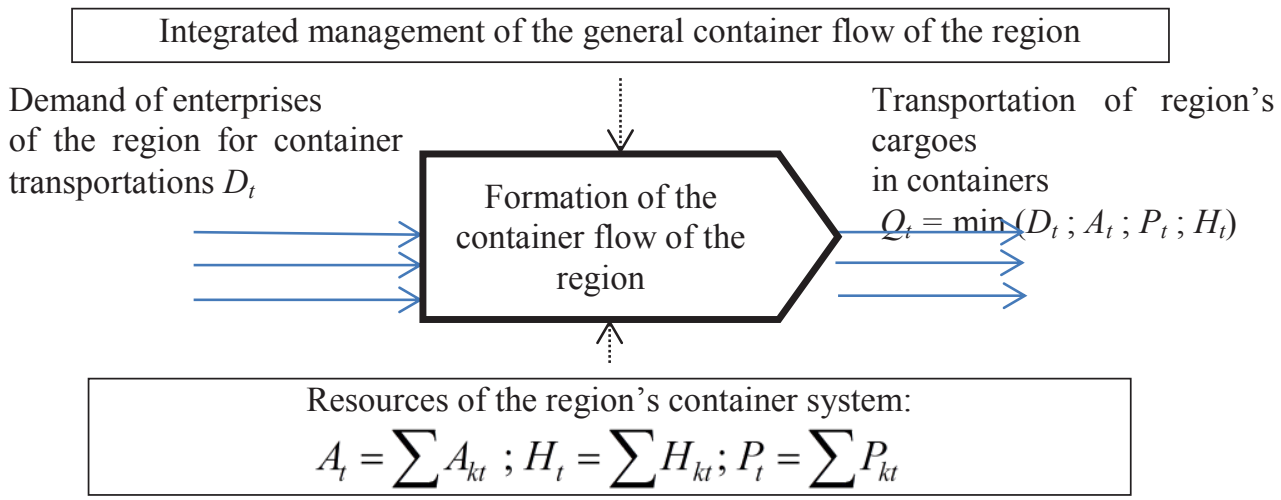

Fig. 2. General model representation of the container system of the region.

The maximum volume of container transportations provided by the system cannot exceed the demand for container transportations and the available resource constraints, that is:

$$
Q_{t}=\min \left(D_{t}, A_{t}, P_{t}, H_{t}\right),
$$

The equation $Q_{t}=D_{t}$ within a given period of time means that the demand for container transportation is fully satisfied, the container system is able to ensure the export of the products fit for transportation in containers. Otherwise, it is required either to create a reserve of resources (within the available opportunities) or to invest into development of a particular resource.

A special role in the presented model is played by the function of integrated control of container traffic: the model allows analyzing two states of the system, i.e., in the absence or presence of integration. In the absence of integration, the activities of the competing links of the regional organizational network are considered separate, and, as a result, many isolated and non-coordinated container flows are formed. It causes the imbalance in loading of container capacities; the emergence of resources shortage in some elements of the container system, with the reserves of others.

The availability of system integration assumes that the organizational network efficiency criterion is not the individual indicators of its individual components, but the system-wide result, which is expressed in maximizing the satisfaction of the region's demand with minimal terms of container traffic processing. 


\section{Experimental data and results}

Let us try the proposed model on the example of the Sverdlovsk region. Figure 3 shows the results of numerical experiments with the Monte Carlo method for forecasting the demand for container transportations. The experiment on the model showed that the region's demand for transportations in containers will not exceed 8,806.7 thousand tons and will not be less than 3,085.3 thousand tons with the probability of the $95 \%$ reliability.

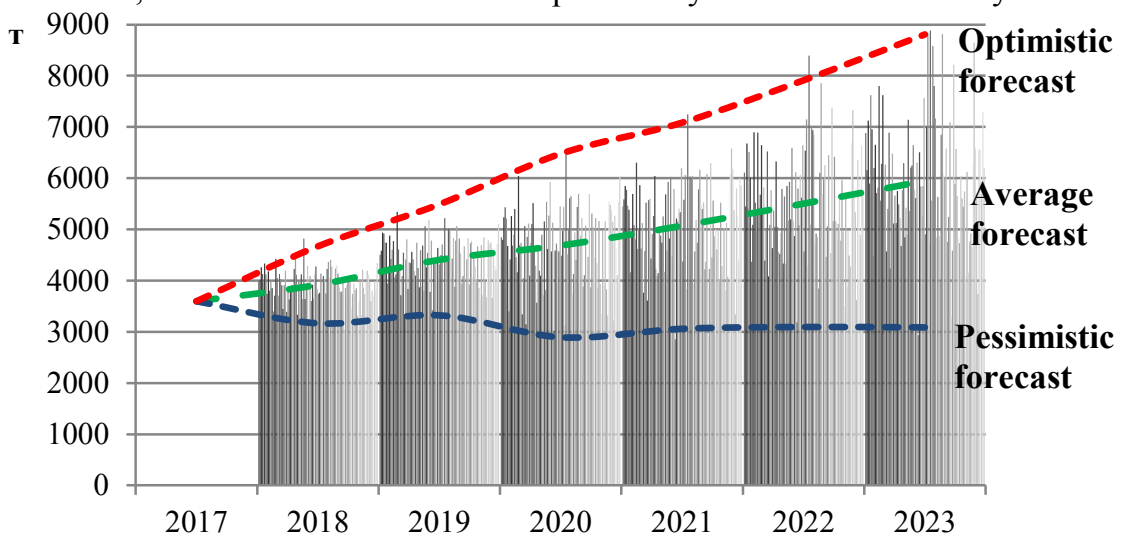

Fig. 3. Results of numerical experiments on forecasting the region's demand for container transportations.

Using model [17-18], the capacity of the container transportation network of the region was assessed with the presence and absence of system integration of links. The result of the system resource development estimation is comparable with the established forecast level of the region's demand for transportations (Fig. 4).

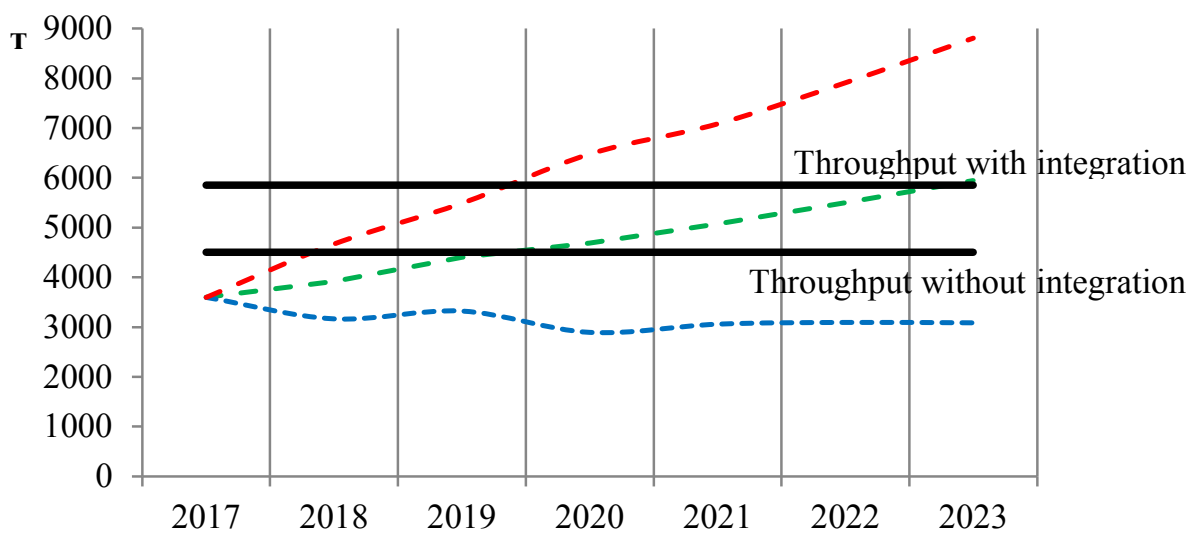

Fig. 4. Results of numerical experiments to estimate the need for development of the container system.

The results of numerical experiments on the model showed that the throughput of the container system in the absence of integration would fully meet the region's demand for transportations until 2019, with the expected containerization growth forecast.

Formation of a system-integrated container network in the region will increase the capacity of the system by $30 \%$ (according to the data of experiments [17]), which will 
increase the period of its uninterrupted operation without additional investments in the terminal infrastructure until 2023.

\section{Conclusion}

The method for forecasting the region's demand for container transportations was proposed depending on the dynamics of the region's economic indices, taking into consideration the random nature of their changes. With the help of the simulation model, the estimation of the required development of the region's container resources was performed to meet the forecast demand. The experiment on the model showed that the integrated flow control allows increasing the container system capacity. Thus, it was determined that the need for technical development of container resources was reduced due to the organizational development of the network.

Implementation of the model in practice will allow making well-founded management decisions regarding expansion of the terminal infrastructure, estimation of prospects and constraints of containerization development taking into consideration the needs and resource possibilities of the region. Further research must be focused on developing approaches to arrangement of interaction of the container organizational network elements based on the system integrator formation in the region.

\section{References}

1. R. Boşneagu, C.E. Coca, F. Sorescu, EIRP Proceedings 10, 360 - 368 (2015).

2. The official web-site of TransContainer JSC, available at: https://trcont.com/en/main (April 10, 2018).

3. S.M. Rezer, O.V. Moskvichev, E.E. Moskvicheva, Transport: science, equipment, management 7, 3-7 (2016). (in Russian)

4. X. Chen, X. Zhu, O. Zhou, Y.D. Wong, Journal of Advanced Transportation 2017, 3128372 (2017).

5. H. Belbo , B. Talbot, Forests 5, 2084-2105 (2014).

6. M. Intihar, T. Kramberger, D. Dragan, PROMET - Traffic\&Transportation 5, 529542 (2017).

7. B. O'Kane, Computer-Aided Design and Applications 11, $44-53$ (2014).

8. T. Keeffe, G. Ormsby, Development in Practice, 25, 843-855 (2015).

9. D. Teodorovic, M. Janic, Transportation Engineering (Butterworth-Heinemann, 2016).

10. N.Yu. Yaroshevich, V.Zh. Dubrovskiy, Izvestia of the USUE 6, 54 - 61 (2014). (in Russian)

11. Yu.V. Dorokhova, N.S. Goncharuk, Central Russian Journal of Social Sciences 1, 3444 (2013). (in Russian)

12. T. Tsekeris, C. Tsekeris, Economic Research 24, 82 - 94 (2011).

13. E.G. Varagouli, T.E. Simos, G.S. Xeidakis, Mathematical and Computer Modelling 42, 817-836 (2005).

14. K. Aksyonov, B. Klebanov, A. Hrenov, Proceedings of the 4th IMACS Symposium on Mathematical Modeling 24, 1414-1420 (2003).

15. V.P. Borovikov, G.I. Ivchenko, Prognozirovanie v sisteme STATISTICA [Forecasting in the STATISTICA system] (Finansy i statistka, Moscow, 2000). (in Russian)

16. Federal State Statistics Service. Russian Federation, available at: http://www.gks.ru/wps/wcm/connect/rosstat_main/rosstat/en/main/ (April 20, 2018) 
17. D.I. Kochneva, Thesis of Candidate of technical sciences, Ural State University of Railway, Yekaterinburg, 2012. (in Russian)

18. D.I. Kochneva, V.M. Say, Herald of the Ural State University of Railway Transport 4, 65-75 (2016). (in Russian) 